\title{
BMJ Open Cross-sectional study of factors associated with community health centre use in a recently urbanised community in Chengdu, China
}

\author{
Danping Liu, ${ }^{1}$ Hongdao Meng, ${ }^{2}$ Debra Dobbs, ${ }^{2}$ Kyaien O Conner, ${ }^{3}$ Kathryn Hyer, ${ }^{2}$ \\ Ningxiu Li, ${ }^{1}$ Xiaohui Ren, ${ }^{1}$ Bo Gao ${ }^{1}$
}

To cite: Liu D, Meng $\mathrm{H}$, Dobbs D, et al. Cross-sectional study of factors associated with community health centre use in a recently urbanised community in Chengdu, China. BMJ Open 2017;7:e014510. doi:10.1136/ bmjopen-2016-014510

- Prepublication history and additional material is available. To view please visit the journal (http://dx.doi.org/10.1136/ bmjopen-2016-014510)

Received 29 September 2016 Revised 24 March 2017 Accepted 29 March 2017

\section{CrossMark}

${ }^{1}$ Department of Health and Social Behavior, School of Public Health, Sichuan University, Chengdu, China

${ }^{2}$ School of Aging Studies, College of Behavioral \&

Community Sciences, University of South Florida, Tampa, Florida, USA

${ }^{3}$ Department of Mental Health Law \& Policy, College of Behavioral \& Community Sciences, University of South Florida, Tampa, Florida, USA

Correspondence to Dr Hongdao Meng; meng@ usf.edu

\section{ABSTRACT}

Objectives Public investment in community health centres (CHCs) has been increasing as a response to rapid urbanisation in China. The objectives of this study were: (1) to examine factors associated with $\mathrm{CHC}$ use among residents from a recently urbanised community in western China and (2) to describe satisfaction with $\mathrm{CHC}$ among users.

Design Cross-sectional design.

Setting A community recently converted to urban status with a newly constructed $\mathrm{CHC}$ in Southwest China.

Participants A random sample of 2259 adults in the Hezuo community in Chengdu, China, completed the survey in 2013.

Outcome measures Trained staff interviewed study participants in their homes using structured questionnaires. The survey included questions regarding sociodemographics, health status, access to and usage of healthcare, health behaviours and $\mathrm{CHC}$ use. The Andersen's behavioural model of health service use was used to guide multivariable logistic regression modelling in identifying predisposing, enabling and need factors associated with the likelihood of using CHC. Descriptive statistics were used to describe residents' satisfaction with the $\mathrm{CHC}$.

Results A total of $71.8 \%$ of the respondents reported using the $\mathrm{CHC}$ during the past year. Factors influencing adults' $\mathrm{CHC}$ use included: gender, marital status, education level and knowledge of one's blood pressure (predisposing factors); annual household per capita income and walking time to the CHC (enabling factors) and self-rated health as well as physical activities (need factors). CHC users reported modest satisfaction across various aspects of the $\mathrm{CHC}$.

Conclusions Neighbourhood $\mathrm{CHC}$ in urban areas provides important services to these residents living in a recently urbanised community. All three categories of factors in the Andersen model help explain the likelihood of $\mathrm{CHC}$ use. There is much room for improvement in $\mathrm{CHC}$ to enhance customer satisfaction. Future research is needed to improve access to $\mathrm{CHCs}$ and promote their use in urbanised populations with low to modest education.

\section{INTRODUCTION}

According to the Alma-Ata Declaration, access to primary care is crucial for attaining socially and economically productive lives. ${ }^{1}$ To date, a large body of research indicates that access

\section{Strengths and limitations of this study}

- This study used random household sampling to recruit a large community sample of adults who live in a recently urbanised community with access to a newly established community health centre.

- This is the first study to capture access to community health centre in a transitioning urban community with relatively low social-economic status from western China.

- The study findings help policy-makers understand why individuals use community health centres and which aspects of care delivery can be improved to enhance user experience.

- The cross-sectional study design limits the ability to correlational rather than causal inferences regarding the relationship between individual characteristics and community health centre use.

- Self-reported health status measures are not as accurate as those based on physical examinations.

to primary care is one of the key metrics of measuring equity and efficiency in healthcare systems and it can reduce health disparities and avoidable hospitalisations as well as improve overall health status. ${ }^{2-5}$ Community health services (CHS) is well established in developed countries such as the UK, the USA and Australia, and it is considered as one of the most important strategies for the development of primary healthcare in developing countries. ${ }^{6}$ Community health centres (CHCs), mostly government operated, are the cornerstone of China's Urban Healthcare Reform as they are tasked with providing primary care and prevention to neighbourhood residents. ${ }^{6}$

The economic reforms implemented since 1978 have brought rapid economic development and urbanisation to China, with the urban population increasing from 191 (1980) to 779 million in $2015 .^{89}$ But this unprecedented economic growth unfortunately was 
also associated with negative effects such as escalating medical costs and an increasing gap between the demand for and supply of health services, especially in primary care. $^{10}{ }^{11}$ In addition, rapid population ageing coincides with the changing profiles of disease burden from acute infectious and communicable diseases to chronic non-communicable diseases which in turn increase the demand for health services. ${ }^{12}{ }^{13}$ This mismatch between increasing demand and limited healthcare resources has also given rise to increased tensions between patients and medical care providers, with the occasional violent incidences reported by the media. ${ }^{14-16}$ To address these problems, the Chinese State Council initiated a policy in 1997 declaring that China's healthcare in urban areas would focus on strengthening CHS. Since then, CHCs in China have become a critical component of the healthcare system and the Chinese government has strongly supported the establishment of CHCs. Further, it has designed the CHCs to act as the foundation and entry point for the health system. CHCs are responsible for routine primary care, physical rehabilitation and public health practices (family planning and health education). ${ }^{6717}$ As a result, the number of community health facilities has increased dramatically from 8211 to 33736 between 2002 and 2012. ${ }^{6} 17$

The main goal of CHCs is to meet the basic health needs of every resident in the community. Thus, easy access to and satisfaction with CHC services are important benchmarks for policy-makers and healthcare administrators in the continuous development of CHCs. As urbanisation of the Chinese population continues, demand for easy access to high-quality primary care services in the community will remain elevated. ${ }^{18}$ While CHCs have been identified as the preferred policy solution to meet this challenge, ${ }^{19}{ }^{20}$ few studies have used an empirically based behavioural model to examine the factors that influence CHC use. ${ }^{21-23}$ In addition, there is a lack of research on recently urbanised populationswith conflicting evidence suggesting simultaneous improving and worsening health associated with urbanisation in developing countries. ${ }^{92425}$ To address this gap in the literature, this study used the Andersen's behavioural model of health service use to investigate factors associated with adult usage of and satisfaction with CHSs in a newly formed community with a mix of urban and newly urban residents.

The objectives of this study were: (1) to examine factors associated with CHC use among residents from a recently urbanised community in western China and (2) to describe satisfaction with CHC among users. To our knowledge, this study is among the first to examine access to a newly built CHC in a recently urbanised community of a major city in western China, where the pace of economic development has historically lagged behind the more affluent eastern part of the country.

\section{METHODS}

\section{Study setting}

This study used a cross-sectional research design and was conducted in the Hezuo community, one of six subdistricts within a recently developed urban district in Chengdu, Sichuan from January to June in 2013. Chengdu is the capital of Sichuan province in Southwest China and ranked 7th most populous metropolitan area in China with 14 million residents as of $2010 .^{26}$

CHS was developed in Chengdu in the late 1990s. In 2008, the city was selected as one of 28 major cities for the 'The National Urban Community Health Service System Building Project' by the Ministry of Health of China. The nationwide project was aimed at pilot testing of CHS systems and accumulating evidence-based recommendations for further CHS development. ${ }^{16}$ The CHS system in Chengdu consisted of 64 CHCs located in 6 urban districts. Hezuo community (Gaoxin District, population 51389 as of 2012) was chosen for the study because it began the rural-to-urban conversion process in 2006. Prior to the conversion, virtually all residents were farmers and the conversion process is still ongoing. Hezuo CHC, a newly constructed facility opened to the community residents for service in 2007, is staffed by 66 full-time healthcare professionals, including 17 licensed physicians in primary care, 10 licensed physician in traditional Chinese medicine, 28 registered nurses, 10 medical technologists and a contracted supporting staff. Besides the CHC, there are three other hospitals and seven private clinics in the community.

\section{Study participants}

All adult residents aged $\geq 18$ years who resided in Hezuo community for at least 6 months at the time of the survey were eligible to participate in this study. A sample size of 1000 households was determined based on published community health assessment guidelines. ${ }^{27}{ }^{28} \mathrm{~A}$ threestage sampling process was used to ensure the sample is representative of all residents. In stage 1 , all housing developments (similar to the Homeowners Associations in the USA) from the six neighbourhood committees in Hezuo subdistrict were stratified into government-sponsored housing developments (as part of the urbanisation land development) and commercial developments (typically higher priced). In stage 2, building units were randomly sampled from the specific housing developments in stage 1. Computer-generated random numbers were used to determine specific housing developments (stage 1) and building units (stage 2). Finally, systematic random samplings were used to select even or odd number of building units from those identified in stage 2. During the visits to residents' homes, we first explained the aims of the study to an adult from each household. After obtaining informed consent, each participant was interviewed by a trained staff (medical and public health students and community volunteers). The interviews took an average of $20 \mathrm{~min}$ to complete and each participant received a small gift (worth $¥ 10-15$ ) as a token of 
appreciation at the end of the interview. A total of 1008 households agreed to participate in the survey and 2259 adults out of a total of 2653 adults in these households returned questionnaires (a response rate of $85.1 \%$ ). Questionnaires were checked after the interviews for completeness. Twelve records were excluded from the analysis due to missing information on CHC use. The study protocol was approved by the Sichuan University Institutional Review Board.

\section{Measures}

The questionnaire was adapted from a number of structured household surveys on community health assessment. ${ }^{27} 29$ The survey included the following domains of questions: (1) sociodemographics (age, gender, marital status, residence registration, insurance, income, education and occupation); (2) health status and health behaviours (the number of physician diagnosed common chronic conditions, diet and physical activity); (3) access to care (care-seeking behaviour, location of care, type of provider, past year hospital use and healthcare expenditures) and (4) CHC awareness and use. CHC use was operationalised as an affirmative response to the question: "in the past year, have you used the Hezuo CHC for any of the following: physician office visit, physical examination, health information or education?" Among respondents who have used the $\mathrm{CHC}$, they were then asked about their satisfaction with various aspects of care, including staff technical expertise, wait time, quality of the facility, quality of the medical equipment, physicianpatient communication skills, cost of care and overall satisfaction with the CHC. A 5-point Likert scale ranging from 'highly dissatisfied (1)' to 'highly satisfied (5)' was used for all satisfaction questions.

This study adopted the Andersen's behavioural model of health services use to examine the factors associated with the usage of CHS. ${ }^{30} 31$ According to this model, factors contributing to health service use can be classified in three domains: predisposing, enabling and need. Predisposing factors comprise sociodemographic and psychosocial characteristics. ${ }^{32}$ Enabling factors present means or opportunities to access needed health services. Need factors reflect the experience of symptoms or illness that lead an individual to think that seeking health service is necessary. ${ }^{33}$ In this survey, measures of predisposing factors included age, gender, marital status, education level, employment status, knowledge of one's body weight and knowledge of one's blood pressure. Enabling factors included annual household per capita income, medical insurance and walking time from home to the nearest CHC. Measures of need factors included self-rated health, regular physical activities, number of chronic diseases, any acute illness in the 2 weeks prior to the survey and hospitalisation in the previous year.

\section{Statistical analysis}

All research data were entered into EpiData 3.1 for initial processing (validity check, quality control, and verification). ${ }^{34}$ Statistical analyses were conducted using the IBM SPSS version 23.0. We first presented individual characteristics of the sample as a whole and then by CHC use status (non-users vs users). We reported means and SDs as descriptive statistics for continuous variables and percentages for categorical variables. Pearson's $\chi^{2}$ tests were used to examine differences for categorical variables, and $t$-tests were used to examine differences for continuous variables. We then estimated binary logistic regression models to examine the relationship between the independent variables (predisposing factors, enabling factors and need factors) and the likelihood of CHC use. We adjusted the SEs for clustering of individuals in households to allow for intrafamily correlation. ${ }^{35}$ Results with a $p$ value of $<0.05$ were considered statistically significant.

\section{RESULTS}

\section{Sample characteristics}

Individual characteristics of the sample and differences in these characteristics between CHC users and non-users are shown in table 1 . The mean age of the study sample was 46.8 years ( $\mathrm{SD}=17.0$, range: $18-98)$ and $52.6 \%$ were female. The majority of respondents were married $(82.2 \%)$ and only $26.7 \%$ had $>9$ years of formal education. While an overwhelming majority $(96.3 \%)$ were aware of their body weight, less than two-thirds $(70.2 \%)$ knew their recent blood pressure measures. Regarding the enabling factors, only $5.9 \%$ of the sample had annual per capita income of $¥ 50000$ but most $(94.4 \%)$ had medical insurance. Finally, $22.6 \%$ of the participants had at least one chronic disease, $14.1 \%$ had being sick in the 2 weeks prior to the survey and $16.7 \%$ had been hospitalised in the previous year. Overall, $1613(71.8 \%)$ used the CHC in the year before the survey. The comparisons between CHC users and non-users showed that they were different in almost all predisposing (age, gender, marital status, education level, employment status and knowledge of one's blood pressure), enabling (annual household per capita income, medical insurance and walking time from home to the nearest CHC) and need factors (self-rated health, regular physical activities, number of chronic diseases, illness in the 2 weeks before the survey and hospitalisation in prior year). The exception to this was body weight awareness $(\mathrm{p}=0.862)$.

Table 2 shows the results of the multivariable logistic regression model predicting the likelihood of CHC use. Four predisposing factors (female, marital status, education level and knowledge of one's blood pressure), two enabling factors (per capita annual household income and walking time to the nearest $\mathrm{CHC}<15 \mathrm{~min}$ ) and two need factors (self-rated health and regular physical activities) had a significant independent effect on the likelihood CHC use. Women were 39\% more likely than men to have used CHC (OR 1.39, 95\% CI: 1.20 to 1.62). Compared with never married adults, married/ divorced/widowed adults were much more likely to use CHC. Both elementary school education and middle 
Open Access

Table 1 Sample characteristics by community health centre $(\mathrm{CHC})$ usage status

\begin{tabular}{|c|c|c|c|c|}
\hline Factors & $\begin{array}{l}\text { Total } \\
(\mathrm{N}=2247)\end{array}$ & $\begin{array}{l}\text { Non-users } \\
(\mathrm{n}=634)\end{array}$ & $\begin{array}{l}\text { Users } \\
(n=1613)\end{array}$ & p Value \\
\hline \multicolumn{5}{|l|}{ Predisposing factors } \\
\hline Age, mean (SD) & $46.8(17.0)$ & $41.9(15.9)$ & $48.8(17.1)$ & $<0.001$ \\
\hline Age group (\%) & & & & $<0.001$ \\
\hline $18-24$ years & 8.8 & 13.4 & 7.0 & \\
\hline $25-34$ years & 19.1 & 22.7 & 17.7 & \\
\hline $35-44$ years & 20.9 & 25.1 & 19.3 & \\
\hline $45-54$ years & 16.6 & 17.4 & 16.2 & \\
\hline $55-64$ years & 16.1 & 11.7 & 17.8 & \\
\hline$\geq 65$ years & 18.6 & 9.8 & 22.0 & \\
\hline Gender (\%) & & & & $<0.001$ \\
\hline Male & 47.4 & 54.6 & 44.5 & \\
\hline Female & 52.6 & 45.4 & 55.5 & \\
\hline Marital status (\%) & & & & $<0.001$ \\
\hline Never married & 9.3 & 17.8 & 6.0 & \\
\hline Married & 82.2 & 76.7 & 84.4 & \\
\hline Divorced or widowed & 8.4 & 5.5 & 9.5 & \\
\hline Education level (\%) & & & & $<0.001$ \\
\hline No formal education & 9.6 & 8.7 & 10.0 & \\
\hline Elementary school & 29.7 & 23.3 & 32.2 & \\
\hline Middle school & 34.0 & 31.4 & 35.0 & \\
\hline High or vocational school & 16.3 & 21.1 & 14.4 & \\
\hline College and above & 10.4 & 15.5 & 8.4 & \\
\hline Employment status (\%) & & & & $<0.001$ \\
\hline Currently employed & 50.4 & 61.4 & 46.1 & \\
\hline Retired & 6.5 & 3.9 & 7.4 & \\
\hline Not employed & 43.1 & 34.6 & 46.5 & \\
\hline Aware of body weight (\%) & 96.3 & 96.4 & 96.2 & 0.862 \\
\hline Aware of blood pressure level (\%) & 70.2 & 58.2 & 74.9 & $<0.001$ \\
\hline \multicolumn{5}{|l|}{ Enabling factors } \\
\hline $\begin{array}{l}\text { Annual household per capita incon } \\
\text { (\%) }\end{array}$ & & & & 0.001 \\
\hline$\leq ¥ 4999$ & 3.3 & 1.6 & 4.0 & \\
\hline$¥ 5000-9999$ & 15.0 & 15.5 & 14.9 & \\
\hline$¥ 10000-29999$ & 63.3 & 60.3 & 64.5 & \\
\hline$¥ 30000-49999$ & 12.5 & 15.6 & 11.3 & \\
\hline$\geq ¥ 50000$ & 5.9 & 7.1 & 5.4 & \\
\hline Has medical insurance (\%) & 94.4 & 92.1 & 95.4 & 0.004 \\
\hline Walking time from home to the $\mathrm{CH}$ & & & & 0.029 \\
\hline$\leq 15 \mathrm{~min}$ & 86.3 & 83.8 & 87.4 & \\
\hline$>15 \mathrm{~min}$ & 13.7 & 16.2 & 12.6 & \\
\hline \multicolumn{5}{|l|}{ Need factors } \\
\hline Self-rated health & & & & $<0.001$ \\
\hline Very poor or poor & 2.5 & 0.6 & 3.3 & \\
\hline Fair & 18.6 & 11.8 & 21.2 & \\
\hline
\end{tabular}

Continued 


\begin{tabular}{|c|c|c|c|c|}
\hline Factors & $\begin{array}{l}\text { Total } \\
(\mathrm{N}=2247) \\
\end{array}$ & $\begin{array}{l}\text { Non-users } \\
(n=634)\end{array}$ & $\begin{array}{l}\text { Users } \\
(n=1613)\end{array}$ & p Value \\
\hline Good & 45.4 & 43.0 & 46.3 & \\
\hline Very good & 33.5 & 44.5 & 29.1 & \\
\hline Number of chronic diseases (\%) & & & & $<0.001$ \\
\hline 0 & 77.4 & 84.9 & 74.5 & \\
\hline 1 & 16.3 & 12.5 & 17.8 & \\
\hline$\geq 2$ & 6.3 & 2.7 & 7.7 & \\
\hline Regular physical activities (\%) & 53.2 & 45.1 & 56.4 & $<0.001$ \\
\hline $\begin{array}{l}\text { Being sick in the } 2 \text { weeks prior to the } \\
\text { survey }(\%)\end{array}$ & 14.1 & 10.3 & 15.6 & 0.001 \\
\hline Hospitalised in prior year (\%) & 16.7 & 10.1 & 19.3 & $<0.001$ \\
\hline
\end{tabular}

school education had significant positive effects on adults using $\mathrm{CHC}$ as compared with those with no formal education, however, the effect of additional education beyond middle school did not reach statistical significance. Those who knew their blood pressure were $87 \%$ more likely to use CHC (OR 1.87, 95\% CI: 1.41 to 2.47). Higher household per capita income was associated with lower likelihood of CHC use. Individuals who lived closer to the CHC (walking time $\leq 15 \mathrm{~min}$ ) were $76 \%$ more likely to use CHC (OR 1.76, 95\% CI: 1.19 to 2.62). Regarding need factors, adults who reported worse self-rated health or having regular physical activities were more likely to use CHC.

Table 3 describes the domain satisfaction as well as the overall satisfaction with the CHC among those who used CHC ( $n=1614)$. The great majority of CHC users were satisfied with various aspects of the CHC, with modest overall satisfaction scores of $3.87(\mathrm{SD}=0.49)$ on a 5-point scale. Respondents were slightly more satisfied with communication with providers (mean score of 3.92) and the perceived compassionate care (mean score of 3.96) and less satisfied with quality of medical equipment (mean score of 3.59). However, nine individuals were highly dissatisfied with the quality of medical equipment and one individual was highly dissatisfied with communication with providers.

\section{DISCUSSION}

This study is the first to focus on the usage of and satisfaction with CHC in a sample of adults living in a newly urbanised community in the seventh largest city in China. The findings indicate that predisposing, enabling and need factors all help explain the likelihood of CHC use among adults. There is some evidence suggesting that residents with low to modest education and income are more likely to use CHC, whereas those with high education/income were less likely. Convenience factor (walking distance) plays an important role in determining realised access to CHC.
The health consequences of rapid urbanisation such as the increase of chronic diseases are more and more evident in China. For example, chronic diseases were estimated to contribute to $80 \%$ of deaths and $70 \%$ of disability-adjusted life years lost in China. ${ }^{36}{ }^{37}$ Urbanisation among formerly suburban farming populations brings unique challenges in terms of increases in pollution, occupational hazards, exposure to known health risk factors, such as diet that include more processed foods and more unhealthy food choices and physical inactivity, ${ }^{9}$ despite its positive effects in terms of better urban planning, housing, health services and education. Through health education, health promotion and disease prevention services, CHCs could potentially be an important mechanism to counteract the detrimental effects of urbanisation in these communities.

For individuals seeking healthcare information and services, CHCs are among a wide range of options ranging from standalone or pharmacy-affiliated private clinics to tertiary hospitals equipped with state-of-the-art diagnostic and treatment facilities. Despite the policy efforts to promote CHC use as the first choice for primary care, many residents in both urban and rural areas continue to rely heavily on tertiary hospitals. ${ }^{20}{ }^{38}$ The finding that $28.2 \%$ of study respondents did not use CHCin the last year suggests that there is still much room for improvement. Public health policy may need to continue promoting the role of CHC in enabling access to high-quality primary care. Studies have shown that many residents may not be aware of services provided at CHC and there are large variations in awareness of CHCs and their services among residents. ${ }^{72839}$ For example, a study in the southern city of Zhuhai showed that $38.4 \%$ of those surveyed were unaware of services provided by $\mathrm{CHC}^{40}$ and another study of the eastern province of Jiangsu found 25.1\% of residents were unaware of their community CHC. ${ }^{41}$ Second, there is also evidence that some residents may not trust CHC as high-quality health services providers as compared with tertiary hospitals, which partially contributes to the crowding of those hospitals. ${ }^{17}$ Third, residents' 
Open Access

Table 2 Multivariable logistic regression model examining factors associated with the likelihood of using community health centre $(\mathrm{CHC})$

\begin{tabular}{|c|c|c|c|}
\hline & OR $^{\star}$ & p Value & $95 \% \mathrm{Cl}$ \\
\hline \multicolumn{4}{|l|}{ Predisposing factors } \\
\hline \multicolumn{4}{|l|}{ Age group } \\
\hline $18-24$ years & Reference & & \\
\hline $25-34$ years & 0.86 & 0.565 & 0.52 to 1.43 \\
\hline $35-44$ years & 0.67 & 0.148 & 0.39 to 1.15 \\
\hline $45-54$ years & 0.65 & 0.131 & 0.37 to 1.14 \\
\hline $55-64$ years & 1.00 & 0.991 & 0.51 to 1.94 \\
\hline$\geq 65$ years & 1.36 & 0.400 & 0.66 to 2.81 \\
\hline Female & 1.39 & $<0.001$ & 1.20 to 1.62 \\
\hline \multicolumn{4}{|l|}{ Marital status } \\
\hline Never married & Reference & & \\
\hline Married & 2.79 & $<0.001$ & 1.72 to 4.50 \\
\hline Divorced or widowed & 3.01 & 0.001 & 1.56 to 5.81 \\
\hline \multicolumn{4}{|l|}{ Education level } \\
\hline No formal education & Reference & & \\
\hline Elementary school & 1.79 & 0.008 & 1.16 to 2.75 \\
\hline Middle school & 2.35 & 0.001 & 1.45 to 3.81 \\
\hline High or vocational school & 1.49 & 0.146 & 0.87 to 2.55 \\
\hline College and above & 1.48 & 0.216 & 0.80 to 2.75 \\
\hline \multicolumn{4}{|l|}{ Employment status } \\
\hline Employed & Reference & & \\
\hline Retired & 1.15 & 0.670 & 0.60 to 2.19 \\
\hline Not employed & 1.05 & 0.727 & 0.80 to 1.37 \\
\hline Knowledge of one's body weight & 0.79 & 0.548 & 0.37 to 1.69 \\
\hline Knowledge of one's blood pressure & 1.87 & $<0.001$ & 1.41 to 2.47 \\
\hline \multicolumn{4}{|l|}{ Enabling factors } \\
\hline \multicolumn{4}{|c|}{ Annual household per capita income (Yuan) } \\
\hline$\leq ¥ 4999$ & Reference & & \\
\hline$¥ 5000-9999$ & 0.30 & 0.010 & 0.12 to 0.75 \\
\hline$¥ 10000-29999$ & 0.35 & 0.015 & 0.15 to 0.82 \\
\hline$¥ 30000-49999$ & 0.25 & 0.003 & 0.10 to 0.61 \\
\hline$\geq ¥ 50000$ & 0.26 & 0.009 & 0.10 to 0.71 \\
\hline Has medical insurance & 1.31 & 0.271 & 0.81 to 2.10 \\
\hline Walking time to the $\mathrm{CHC} \leq 15 \mathrm{~min}$ & 1.76 & 0.005 & 1.19 to 2.62 \\
\hline \multicolumn{4}{|l|}{ Need factors } \\
\hline \multicolumn{4}{|l|}{ Self-rated health } \\
\hline Very good & Reference & & \\
\hline Good & 1.41 & 0.027 & 1.04 to 1.90 \\
\hline Fair & 1.78 & 0.008 & 1.16 to 2.71 \\
\hline Very poor & 4.43 & 0.013 & 1.36 to 14.35 \\
\hline \multicolumn{4}{|l|}{ Number of chronic diseases } \\
\hline 0 & Reference & & \\
\hline 1 & 0.84 & 0.342 & 0.59 to 1.20 \\
\hline$\geq 2$ & 1.16 & 0.644 & 0.62 to 2.15 \\
\hline
\end{tabular}


Table 2 Continued

\begin{tabular}{llll} 
& OR $^{*}$ & p Value & 95\% Cl \\
\hline Regular physical activities & 1.35 & 0.033 & 1.03 to 1.78 \\
Being sick in the 2 weeks prior to the survey & 0.81 & 0.282 & 0.56 to 1.18 \\
Hospitalised in prior year & 0.78 & 0.160 & 0.55 to 1.10 \\
\hline
\end{tabular}

${ }^{*}$ Adjusted for all covariates listed.

knowledge about the importance of preventive care and health promotion may not be adequate. ${ }^{7}$ This is especially true for the newly urbanised residents, the majority of whom were farmers not long before and they often lacked enough health literacy due to poor socioeconomic status. $^{42}$ Therefore, it is important to promote health education among community residents and to improve their knowledge of the health service functions of CHCs and their importance in maintaining and improving health through regular visits to CHCs.

Understanding the factors affecting the use of CHCs is important in ensuring equal access to CHCs among residents. This study adopted the Andersen model to identify what determines CHC use among adults by categorising associated factors as predisposing factors, enabling factors and need factors. Results revealed that the above three types of factors affected the usage of CHC among adults. Compared with males, a higher proportion of females had used CHC in the past year. This finding is consistent with other related studies that found females to be more likely to have contact with the healthcare system than males. ${ }^{1043}$ Other studies also reported that lower education was associated with choosing $\mathrm{CHC}$ over hospital for initial treatment. ${ }^{610}$ In this study, we observed a positive association between elementary and middle school education and CHC use compared with those with no formal education. This study also found that marital status was significantly associated with CHC use and married and divorced or widowed adults were more likely to use CHC as compared with never-married adults. A similar result was found in Blackwell's study that never-married adults in Canada were less likely to use hospitalisation compared with married adults. ${ }^{33}$ In addition, we found that knowing about one's blood pressure had a positive association with CHC use. While this may be due to better health awareness of community health resources (such as the CHC) among people who check their blood pressures regularly, we cannot rule out the possibility that those residents who used the CHC are more likely to have their blood pressures checked due to the cross-sectional design of the study.

As an enabling factor, household per capita income was found to have different effects on healthcare use in previous studies. Recent studies have found that lower household income was the consistent predictor of lower use of healthcare services. ${ }^{44-46}$ In our study, household per capita income was found to be negatively associated with CHC use in that adults with higher household income were less likely to use CHC. In China, many residents with higher household income may prefer to out-patient services at tertiary hospitals with better technologies and perceived higher quality. ${ }^{38}$ Other reasons that may

Table 3 Satisfaction with the community health centre $(\mathrm{CHC})$ among $\mathrm{CHC}$ users

\begin{tabular}{|c|c|c|c|c|c|c|}
\hline Items & $\begin{array}{l}\text { Mean* } \\
\text { (SD) }\end{array}$ & $\begin{array}{l}\text { Highly } \\
\text { dissatisfied, } \\
\text { n (\%) }\end{array}$ & $\begin{array}{l}\text { Dissatisfied, } \\
\text { n (\%) }\end{array}$ & $\begin{array}{l}\text { Neutral, } \\
\text { n (\%) }\end{array}$ & $\begin{array}{l}\text { Satisfied, } \\
\text { n (\%) }\end{array}$ & $\begin{array}{l}\text { Highly satisfied, } \\
\text { n (\%) }\end{array}$ \\
\hline $\begin{array}{l}\text { Technical ability } \\
\text { of the staff }\end{array}$ & $3.74(0.59)$ & 0 & $50(3.1)$ & $372(23.1)$ & 1134 (70.3) & $57(3.5)$ \\
\hline Wait time & $3.73(0.52)$ & 0 & $23(1.4)$ & 418 (25.9) & 1139 (70.6) & $33(2.0)$ \\
\hline Facilities & $3.81(0.49)$ & 0 & $4(0.2)$ & 361 (22.4) & 1181 (73.2) & $67(4.2)$ \\
\hline $\begin{array}{l}\text { Communication } \\
\text { with the } \\
\text { providers }\end{array}$ & $3.92(0.50)$ & $1(0.1)$ & $12(0.7)$ & 227 (14.1) & 1251 (77.6) & $122(7.6)$ \\
\hline Overall & $3.87(0.49)$ & 0 & $9(0.6)$ & 282 (17.5) & 1230 (76.3) & $92(5.7)$ \\
\hline
\end{tabular}

${ }^{*}$ On a scale of 1 (highly dissatisfied) to 5 (highly satisfied). 
help explain low $\mathrm{CHC}$ use include the lack of awareness of specific services provided by CHC, as well as the lack of trust for CHC and its providers. ${ }^{1710}$ To improve the utilisation of CHC, media campaigns and outreach activities should be considered to supplement reimbursement policy favouring CHC use for primary care. ${ }^{14}$

Previous studies showed that distance is an important determinant of health service demand and can affect the usage of health services. ${ }^{10} 47$ Our finding that shorter walking time (distance) was in fact associated with higher likelihood of CHC use. Results revealed, to some extent, that site selection for future CHCs should consider geographic locations that maximise convenience to as many residents as possible. In addition, regular physical activities were found to be associated with higher likelihood of CHC use among adults in the current study. The explanation may be higher awareness of benefits of visiting a CHC among those with regular physical activities. Somewhat unexpected, the number of chronic conditions were not statistically significant predictors of CHC use. This may partially reflect the underuse of $\mathrm{CHC}$ as a provider for chronic disease management and follow-up.

The results of satisfaction with the $\mathrm{CHC}$ revealed that the great majority of users were either neutral or satisfied and the levels of satisfaction were quite modest across various aspects of the CHC. While residents were slightly more satisfied with the communication with providers and the perceived compassionate care, they were less satisfied with the quality of medical equipment in the CHC. This finding suggests that the government may need to allocate additional resources to improve the infrastructure and medical equipment, as well as the training and qualifications of CHC providers. Evidence exists that partnerships between CHCs and tertiary hospitals may help bridge the gap between providers' clinical skills and consumer demand for quality in healthcare. ${ }^{16}$

This study has a number of limitations. The major limitation is the cross-sectional design which precludes making causal inferences about the relationship between predictors and the likelihood of CHC use. In addition, some predisposing factors such as health beliefs have not been taken into consideration, which may also impact the usage of health services. Finally, while this study is among the first to examine access to $\mathrm{CHC}$ among recently urbanised populations in western China, the findings may not be generalisable to other regions in China.

\section{CONCLUSIONS}

Although important progress has been made in the development and strengthening of CHCs in urban areas and many community-dwelling adults are using CHCs, results of our investigation suggest that there is still room for improvement in the usage of CHCs for primary care. The majority of residents seemed to use the CHC to meet their primary care needs but more education and consumer outreach programmes are needed to further enhance the role of CHCs in promoting the awareness of health information, health promotion and behaviour change in the communities where people work and live. Satisfaction survey results suggest that more resources are needed to strengthen the CHC infrastructure and staff competency. CHC's participation in health promotion campaigns targeting at community residents may also be necessary to combat the negative consequences of urbanisation especially among a large number of non-urban populations with limited education but new-found income/asset due to urban land development and substantial appreciation in property value. Future studies should examine to what extent certain predisposing factors, enabling factors and need factors can be modified to improve access to CHCs.

Correction notice This paper has been amended since it was published Online First. Owing to a scripting error, some of the publisher names in the references were replaced with 'BMJ Publishing Group'. This only affected the full text version, not the PDF. We have since corrected these errors and the correct publishers have been inserted into the references.

Acknowledgements The authors wish to acknowledge research support by the Community Health Foundation of Chengdu, which makes this project possible. They would also like to thank all Hezuo community residents for their participation. The authors thank all undergraduate and graduate students from Sichuan University, as well as staff members at Hezuo subdistrict who contributed to data collection. Dr Liu completed the work as a visiting scholar in the School of Ageing Studies at the University of South Florida in 2015.

Contributors All authors contributed to the preparation and editing of the manuscript. DL, NL, XR and BG: designed the study, collected the data and conducted the literature review. DL and HM: analysed the data and drafted the manuscript. DD, KOC and KH: contributed to data interpretation and critical revisions of the manuscript.

Funding This work was supported by Hezuo Sub'District of Chengdu, China. DL was supported by funding from the China Scholarship Council.

Competing interests None declared.

Ethics approval Sichuan University Institutional Review Board.

Provenance and peer review Not commissioned; externally peer reviewed.

Data sharing statement No additional data are available.

Open Access This is an Open Access article distributed in accordance with the Creative Commons Attribution Non Commercial (CC BY-NC 4.0) license, which permits others to distribute, remix, adapt, build upon this work non-commercially, and license their derivative works on different terms, provided the original work is properly cited and the use is non-commercial. See: http://creativecommons.org/ licenses/by-nc/4.0/

(c) Article author(s) (or their employer(s) unless otherwise stated in the text of the article) 2017. All rights reserved. No commercial use is permitted unless otherwise expressly granted.

\section{REFERENCES}

1. Dib HH, Sun P, Minmin Z, et al. Evaluating community health centers in the city of Dalian, China: how satisfied are patients with the medical services provided and their health professionals? Health Place 2010;16:477-88.

2. Starfield B, Shi L, Macinko J. Contribution of primary care to health systems and health. Milbank Q 2005;83:457-502.

3. Shi L, Macinko J, Starfield B, et al. Primary care, social inequalities and all-cause, heart disease and Cancer mortality in US counties: a comparison between urban and non-urban areas. Public Health 2005;119:699-710.

4. Wang $\mathrm{H}$, Gusmano MK, Cao Q. An evaluation of the policy on community health organizations in China: will the priority of 
new healthcare reform in China be a success? Health Policy 2011;99:37-43.

5. Hu H, Liang W, Liu M, et al. Establishment and evaluation of a model of a community health service in an underdeveloped area of China. Public Health 2010;124:206-17.

6. Tang C, Luo Z, Fang P, et al. Do patients choose community health services (CHS) for first treatment in China? results from a community health survey in urban areas. J Community Health 2013;38:864-72.

7. Pan X, Dib HH, Wang X, et al. Service utilization in community health centers in China: a comparison analysis with local hospitals. BMC Health Serv Res 2006;6:93.

8. Department of Economic and Social Affairs. World Population Prospects: the 2015 Revision, Data Booklet. United Nations: Department of Economic and Social Affairs 2015.

9. Gong P, Liang S, Carlton EJ, et al. Urbanisation and health in China. Lancet 2012;379:843-52.

10. Gong Y, Yin X, Wang Y, et al. Social determinants of community health services utilization among the users in China: a 4-year crosssectional study. PLoS One 2014;9:e98095.

11. Tang S, Meng Q, Chen L, et al. Tackling the challenges to health equity in China. Lancet 2008;372:1493-501.

12. Eckert S, Kohler S. Urbanization and health in developing countries: a systematic review. World Health Popul 2014;15:7-20.

13. Van de Poel E, O'Donnell O, Van Doorslaer E. Urbanization and the spread of diseases of affluence in China. Econ Hum Biol 2009;7:200-16.

14. He AJ, Qian J. Explaining medical disputes in Chinese public hospitals: the doctor-patient relationship and its implications for health policy reforms. Health Econ Policy Law 2016;11:1-20.

15. Peng W, Ding G, Tang Q, et al. Continuing violence against medical personnel in China: a flagrant violation of chinese law. Biosci Trends 2016;10:240-3

16. Hou W, Fan H, Xu J, et al. Service functions of private community health stations in China: a comparison analysis with governmentsponsored community health stations. J Huazhong Univ Sci Technolog Med Sci 2012;32:159-66.

17. Bhattacharyya O, Delu Y, Wong ST, et al. Evolution of primary care in China 1997-2009. Health Policy 2011;100:174-80.

18. Chen Z. Launch of the health-care reform plan in China. Lancet 2009;373:1322-4.

19. Liu Q, Wang B, Kong $Y$, et al. China's primary health-care reform Lancet 2011;377:2064-6.

20. Wang $\mathrm{HH}$, Wang JJ, Wong SY, et al. The development of urban community health centres for strengthening primary care in China: a systematic literature review. Br Med Bull 2015;116:Idv043-153.

21. Chung VC, Ma PH, Wang $\mathrm{HH}$, et al. Integrating traditional chinese medicine services in community health centers: insights into utilization patterns in the pearl river region of china. Evid Based Complement Alternat Med 2013;2013:1-8.

22. Parry J. GP based primary care is only just starting to emerge in China. BMJ 2010;341:c5049.

23. Wang $\mathrm{HH}$, Wong SY, Wong MC, et al. Patients' experiences in different models of community health centers in southern China. Ann Fam Med 2013;11:517-26

24. Allender S, Wickramasinghe K, Goldacre M, et al. Quantifying urbanization as a risk factor for noncommunicable disease. J Urban Health 2011;88:906-18.

25. Angkurawaranon $\mathrm{C}$, Jiraporncharoen $\mathrm{W}$, Chenthanakij $\mathrm{B}$, et al. Urbanization and non-communicable disease in Southeast Asia: a review of current evidence. Public Health 2014;128:886-95.
26. Feng $X$, Ye N, Ye N. The sixth chinese Census: results from the 25 major cities. Statistics and Management 2012;3:50-1.

27. Dong Y, Chen B. Community Health Assessment: a Technical Manual. Beijing: Peking Univeristy Medical Center Press, 2008.

28. Chai $\mathrm{Y}, \mathrm{Xu} \mathrm{H}$, Wang $\mathrm{W}$, et al. A survey of factors associated with the utilization of community health centers for managing hypertensive patients in Chengdu, China. PLoS One 2011;6:e21718.

29. Paniz VM, Fassa AG, Maia MF, et al. Measuring access to medicines: a review of quantitative methods used in household surveys. BMC Health Serv Res 2010;10:146.

30. Andersen R, Newman JF. Societal and individual determinants of medical care utilization in the United States. Milbank Mem Fund Q Health Soc 1973;51:95-124.

31. Andersen RM. Revisiting the behavioral model and access to medical care: does it matter? J Health Soc Behav 1995;36:1-10.

32. Walen HR, Cronan PA, Bigatti SM. Factors associated with healthcare costs in women with Fibromyalgia. Am J Manag Care 2001;7 Spec No:Sp39-47.

33. Blackwell DL, Martinez ME, Gentleman JF, et al. Socioeconomic status and utilization of health care services in Canada and the United States: findings from a binational health survey. Med Care 2009;47:1136-46.

34. A comprehensive tool for validated entry and documentation of data [computer program]. Version 3.1. Odense Denmark: The EpiData Association. 2004.

35. White $\mathrm{H}$. Maximum Likelihood estimation of Misspecified models. Econometrica 1982;50:1-25

36. Hu X, Huang J, Lv Y, et al. Status of prevalence study on multimorbidity of chronic disease in China: systematic review. Geriatr Gerontol Int 2015;15:1-10.

37. Wang L, Kong L, Wu F, et al. Preventing chronic diseases in China. Lancet 2005;366:1821-4.

38. Li J, Wang P, Kong X, et al. Patient satisfaction between primary care providers and hospitals: a cross-sectional survey in Jilin Province, China. Int J Qual Health Care 2016;28:346-54.

39. Shi Y, Ji Y, Sun J, et al. Lack of health risk awareness in low-income chinese youth migrants: assessment and associated factors. Environ Health Prev Med 2012;17:385-93.

40. Ye $\mathrm{H}$, Wang $\mathrm{T}$, Tian $\mathrm{H}$, et al. Utilization of community health service in Xiangzhou district of Zhuhai City and analysis of its influential factors. Chin Gen Prac 2005;8:1990-2.

41. Li C, Zhang K, Hu D. Analysis on the relationship between awareness and utilization of community health service and its influencing factors. Modern Prevent Med 2007;34:1242-5.

42. Li Y. Understanding health constraints among rural-to-urban migrants in China. Qual Health Res 2013;23:1459-69.

43. Bertakis KD, Azari R, Helms LJ, et al. Gender differences in the utilization of health care services. J Fam Pract 2000;49:147-52

44. Girma F, Jira C, Girma B. Health services utilization and associated factors in Jimma Zone, South west Ethiopia. Ethiop J Health Sci 2011;21(Suppl 1):85-94.

45. Luo J, Zhang $X$, Jin $\mathrm{C}$, et al. Inequality of access to health care among the urban elderly in northwestern China. Health Policy 2009;93:111-7.

46. Gao J, Raven JH, Tang S. Hospitalisation among the elderly in urban China. Health Policy 2007;84:210-9.

47. Qian D, Pong RW, Yin A, et al. Determinants of health care demand in poor, rural China: the case of Gansu Province. Health Policy Plan 2009;24:324-34 